Western University

Scholarship@Western

Earth Sciences Publications

Earth Sciences Department

2017

\title{
Origin of Graphite in the Southwestern Grenville Province
}

Mehmet F. Taner

Cameron Drever

University of Waterloo

Chris Yakymhuk

University of Waterloo

Fred Longstaffe

The University of Western Ontario, flongsta@uwo.ca

Follow this and additional works at: https://ir.lib.uwo.ca/earthpub

Part of the Geochemistry Commons, and the Geology Commons

Citation of this paper:

Taner, Mehmet F.; Drever, Cameron; Yakymhuk, Chris; and Longstaffe, Fred, "Origin of Graphite in the Southwestern Grenville Province" (2017). Earth Sciences Publications. 24.

https://ir.lib.uwo.ca/earthpub/24 


\title{
ORIGIN OF GRAPHITE IN THE SOUTHWESTERN GRENVILLE PROVINCE
}

\author{
MEHMET F. TANER \\ 1107 Gablefield Private, Gloucester, Ontario K1J 1E4 \\ CAMERON DREVER \& CHRIS YAKYMCHUK* \\ Department of Earth and Environmental Sciences, University of Waterloo, 200 University Ave \\ West, Waterloo, Ontario, N2L $3 G 1$ \\ *cyakymchuk@uwaterloo.ca
}

FRED J. LONGSTAFFE

Department of Earth Sciences, The University of Western Ontario, London, Ontario N6A5B7, Canada

Two graphite deposits in the southwestern Grenville Province are investigated to evaluate the origin of graphitic carbon and test if graphite mineralization is syngenetic or epigenetic. Graphite mineralization in the Bissett Creek deposit is characterized by homogeneously distributed and disseminated graphite flakes (about 1 to $5 \mathrm{~mm}$ in size and 2 to $10 \mathrm{vol} . \%$ ) within graphitic gneisses. Graphite flakes are intergrown with metamorphic minerals, most notably biotite. The Montpellier Graphite showing in Quebec contains graphite concentrations of up to $20 \mathrm{vol} \%$. In contrast to the disseminated and homogenously distributed graphite in the Bissett Creek Deposit, graphite mineralization at Montpellier forms lenses of variable sizes that occur at the top of a calc-silicate unit and as graphite-rich lenses in biotite-sillimanite rich paragneiss. The $\delta^{13} \mathrm{C}$ of graphite ranges from -29 to $-17 \%$ at Bissett Creek and from -18 to $-14 \%$ at Montpellier. Carbon isotope compositions of graphite from both deposits support a biogenic source for the carbon and the spread in $\delta^{13} \mathrm{C}$ can be generated through Rayleigh fractionation. A minor 
36 contribution of inorganic carbon from the devolatilization of carbonate minerals is possible at

37 Montpellier. Mineralization at Bissett Creek and Montpellier is interpreted to represent

38 syngenetic graphite mineralization from organic-rich material during high-temperature

39 metamorphism.

40

41 Keywords: Graphite, Grenville Province, Carbon isotopes, Metamorphic, Gneiss

43 INTRODUCTION

44 As an industrial mineral, graphite is primarily utilized in the steel industry where it is

45 included in bricks that line furnaces (e.g., refractories) to provide strength and resistance to heat

46 and corrosion, used to line ladles and crucibles, and added to steel to increase strength (Luque et

47 al. 2014). Graphite is also used extensively in the automobile industry in gaskets, brake linings

48 and clutch materials. It has a myriad of other industrial uses including electric motors (carbon

49 brushes), batteries, lubricants, pencils, fuel cells, vanadium redox batteries, components of

50 equipment used to generate nuclear and solar energy, golf clubs, hockey sticks, and other

51 sporting goods ( $c f$. , Spence 1920, Hewitt 1965, Garland 1987, Mackinnon \& LeBaron 1992).

52 Increasing demand for green energy has also made graphite a very attractive exploration prospect

53 because of its abundant use in lithium-ion batteries. Thus, it is important to develop and test

54 genetic models of graphite mineralization, which can be used to prioritize exploration targets.

55 Graphite deposits are usually divided into three classes. From relatively low to high

56 value, these classes include: amorphous, flake and vein graphite deposits (Spence 1920, Mitchell

57 1993, Luque et al. 2014). Amorphous graphite represents an aggregate of extremely fine lathes.

58 Flake graphite is the scaly or lamellar form of the mineral, commonly found disseminated in 
metamorphic rocks, such as crystalline limestone, gneisses and schist (e.g. Mitchell 1993). Vein

60 graphite is found in veins or fracture systems along intrusive contacts of pegmatites with host

61 limestones and schists (e.g. Luque et al. 2014).

62 There are currently two main genetic models that describe graphite mineralization. They

63 are the growth of graphite during metamorphic processes, also known as graphitization, and the

64 precipitation of graphite from hydrothermal fluids or melt (Rumble et al. 1986a,b, Papineau et al.

65 2010a, b, Luque et al. 2012, Beyssac \& Rumble 2014,). These processes are end members; some

66 graphite deposits are formed through both metamorphism and hydrothermal deposition

67 (Papineau et al. 2010a,b, Luque et al. 2012). Graphitic carbon deposited from hydrothermal

68 fluids occurs globally, in rocks from all depths in Earth's crust and ranging in age from

69 Precambrian to Tertiary (Rumble 2014). Metamorphic graphite is concentrated in high-

70 temperature metamorphic rocks whereas lower-grade rocks generally contain other carbonaceous

71 material (e.g. coal) in addition to graphite (Okuyama-Kusunose and Itaya, 1987)

72 In the Southwestern Grenville Province, it is unclear if Proterozoic graphite deposits are

73 formed through metamorphic or hydrothermal processes or some combination of both. This is

74 important information for understanding the genesis of graphite (e.g., Luque et al. 2014) and

75 linking metamorphism into global geochemical cycles of carbon (e.g., Galy et al. 2008). Also,

76 understanding the mineralization mechanisms and the influence of different rock types and

77 structures can be used to develop new exploration targets for graphite deposits (e.g., Soman et al.

78 1986). In this contribution, the origin of two graphite deposits in the southwestern Grenville

79 Province (the Bissett Creek deposit in Ontario and the Montpellier graphite showing in Quebec)

80 are evaluated using a combination of field observations, petrology, lithogeochemistry and carbon

81 isotope analysis of graphite. These locations were chosen because the rocks at the Bissett Creek 
82 deposit contain no carbonate minerals whereas graphite mineralization at the Montpellier

83 showing is spatially associated with carbonates. Two possible sources for carbon that form

84 graphite in metamorphic terranes are the breakdown of organic material to graphite at

85 temperatures at and above the amphibolite facies (e.g. Landis, 1971), and the decarbonation of

86 carbonate minerals and precipitation of graphite at amphibolite- to graulite-facies conditions (e.g.

87 Santosh and Omori, 2008). Therefore, this investigation of the Bissett creek deposit and the

88 Montpellier showing allows the two main models of graphite mineralization to be evaluated for

89 two different styles of graphite deposits in the southwestern Grenville Province.

91 REGIONAL GEOLOGY

92 Most graphite mineralization in Canada is located in the Grenville Province of Southern

93 Quebec and Central Ontario (Spence 1920, Hewitt 1965, Garland 1987, Simandl 1989,

94 Mackinnon \& LeBaron 1992). The metallogeny of the structural zones of the Grenville province

95 was well defined by Sangster et al. (1992). The southwestern Grenville Province consists of

96 granitic gneisses, metavolcanic rocks, metasedimentary schists and impure marbles that were

97 deformed and metamorphosed during the Grenville orogen (Wynne-Edwards 1972, Carr et al. 98 2000, Rivers et al. 2012).

99 The two graphite deposits studied here are located in separate parts of the southwestern

100 Grenville Province. The Bissett Creek deposit is part of the Mesoproterozoic gneisses of the

101 Central Gneiss Belt (Carr et al. 2000), which is also known as the Ottawa River Gneiss Complex

102 (Rivers \& Schwerdtner 2015). In the vicinity of the deposit, the geology is interpreted to

103 represent reworked rocks of the former Laurentian margin (e.g., Carr et al. 2000). The

104 Montpellier graphite showing is found in the Composite Arc Belt, which represents 
105 allochthonous Mesoproterozoic volcanic arcs and sedimentary rocks that accreted to the

106 southeast margin of Laurentia during the Grenville orogen (e.g., Carr et al. 2000).

107

108 GeOlogy of THE BissetT CREEK GRAPHITE DEPOSIT

109 Location

110 The Bissett Creek graphite property (Fig. 1) belongs to the Northern Graphite

111 Corporation of Ottawa and it is easily accessible by the Trans-Canada Highway (Highway 17),

112 approximately $53 \mathrm{~km}$ east of the town of Mattawa. All mining claims are located in Maria

113 Township, Ontario in the County of Renfrew, Province of Ontario.

114

115 Field relationships and lithogeochemistry

116 Graphite mineralization at the Bissett Creek deposit is characterized by homogeneously

117 distributed graphite flakes (about 1 to $5 \mathrm{~mm}$ in size) within biotite-rich quartzofeldspathic

118 gneisses (Fig. 2a; Taner 2010, 2013). The graphitic gneisses are subdivided into: (1) biotite-rich

119 quartzofeldspathic gneiss, (2) diopside-tremolite-biotite graphitic gneiss, and (3) graphite-poor

120 sillimanite-garnet gneiss, which occurs at the boundary between the graphitic and barren

121 gneisses. Where observed, the contacts between each of the different graphitic gneiss units are

122 gradational over centimetres to metres. The total thickness of graphitic gneisses, from west to

123 east, varies from $25 \mathrm{~m}$ to $90 \mathrm{~m}$, as determined by drilling. At the surface, the graphitic gneisses

124 form a distinctive recessive weathering unit (generally red-orange to pale yellow-brown

125 weathering) and are commonly exposed along rock cuts, hilltops and occasional cliff faces (Fig.

126 2b). When weathered, graphite flakes are easily picked out of the rock. 
128 the graphitic gneiss. Drilling intersections internal to the deposit vary in thickness from 1 to 20

$129 \mathrm{~m}$. In drill core, sharp contacts between the barren gneiss and the graphitic gneiss suggest an

130 intrusive relationship. The gneissic units are intruded by metre-scale pegmatites (Fig. 2c), and in

131 one location, by a metre-scale lamprophyre dyke (Fig. 2d).

132 The pegmatite unit is a light grey to pinkish, quartz-feldspar rich rock with some large

133 dark brown flakes of biotite and rare pyrite. Pegmatite zones locally contain rare graphite

134 mineralization in the form of flakes intercalated with biotite. Biotite enrichment occurs within

135 the contact zones with the host gneisses.

136 The lamprophyre dyke unit is fine grained, dark green and exhibits sharp intrusive

137 contacts with the graphitic and barren gneiss units. The lamprophyre dykes do not contain

138 graphite mineralization. Lamprophyre dykes are subvertical and generally strike east-west (Fig.

$1392 \mathrm{~d})$.

140 Foliations are shallowly dipping to sub-horizontal across the property. The graphitic

141 gneiss has a moderate dip to the east from 5 to 20 degrees and the high-grade layer dips 20 to 30

142 degrees south. Gignac et al. (2012) report two generations of folding present on the property. The

143 primary deformation event produced isoclinal folds (Fig. 2a), which were then refolded during a

144 second event into large open folds (Gignac et al. 2012).

\section{Petrographic observations}

147 The biotite-rich, quartzofeldspathic graphitic gneiss is fine to medium-grained, light to 148 dark grey, and contains between 2 and 10 vol.\% homogeneously disseminated, graphite flakes 149 (Fig. 3a). The biotite-rich, quartzofeldspathic gneiss is composed of centimetre-to decimetre- 
scale, quartz-feldspar rich leucosomes that have lower amounts of graphite and display augen-

151 gneiss textures. Leucosomes alternate with millimetre- to centimetre-scale biotite and graphite-

152 rich layers. Biotite-rich layers contain between 4 and 10 vol.\% graphite that is homogeneously

153 distributed (Fig. 4a). Graphite flakes are 1-5 mm in length (Fig. 4b) and are intimately associated

154 with biotite (Fig. 4c). Disseminated sulfides (1-2 vol.\%, mostly pyrrhotite) occur within biotite-

155 rich layers. Garnet and muscovite are present in some samples from this unit.

156 The diopside-tremolite-biotite gneiss is fine- to medium-grained and is composed of

157 quartz-feldspar-rich layers ( $\mathrm{mm}$ to $\mathrm{dm}$ ) that alternate with diopside-tremolite-biotite-graphite

158 rich layers (Fig. 3b). It is located in the upper part of the mineralized graphite zones at Bissett

159 Creek. Graphite comprises 3 to 6 vol.\% of this unit and is homogeneously distributed as

160 disseminated graphite flakes (Fig. 4d). Trace amounts (1-2 vol.\%) of disseminated sulfide

161 minerals (mostly pyrrhotite) are also present. Some parts of this unit also contain garnet, but it is

162 frequently found in close association with pegmatite intrusions. Minerals are generally

163 granoblastic in this unit.

164 The biotite-sillimanite-garnet gneiss unit is medium-grained and contains a well-defined

165 foliation defined by the parallel alignment of biotite and sillimanite lathes (Fig. 3c). It is

166 composed of millimetre- to centimetre-scale, leucocratic layers that alternate with millimetre- to

167 decimetre-scale, biotite-sillimanite-garnet-rich layers. The melanocratic layers are composed of

168 quartz and feldspar with up to 15 vol.\% biotite, up to 15 vol.\% sillimanite and up to 5 vol.\%

169 garnet. Graphite flakes are rare and are usually associated with disseminated pyrite and

170 pyrrhotite (1-2 vol.\%). 
The barren gneiss unit is found structurally above and below the graphitic gneiss units.

172 This unit is composed of pink quartzofeldspathic leucosome that alternates with relatively

173 biotite-rich melanosome (Fig. 3d). This unit contains no graphite.

175 Economic Geology

176 The graphitic carbon contents of select graphitic units reported in Gignac et al. (2012) are

177 summarized in Table 1 and displayed in Figure 5. Samples were analyzed for graphitic carbon at 178 SGS Laboratories using the CSA05V analytical package, which uses a roast/coulometry method.

179 The diopside-tremolite-biotite gneiss shows a range of graphitic carbon contents from $\sim 1$ to 3 180 wt.\%. The biotite-rich quartzofeldspathic gneiss unit contains between $\sim 1$ and 4 wt.\% graphitic 181 carbon. The median graphitic carbon content of the biotite-rich quartzofeldspathic gneiss is $\sim 1 \%$ 182 higher than the diopside-tremolite-biotite gneiss (Fig. 5). Graphite particles generally contain 183 20-30 vol.\% interlayered mica (Fig. 4c). Measured resources of graphite at the Bissett Creek 184 deposit are estimated at 69.8 million tonnes grading $1.74 \%$ graphitic carbon based on a $1.02 \%$ 185 graphitic carbon cutoff grade (Gignac et al. 2012, Leduc 2013). The inferred resource is 24 186 million tonnes grading $1.65 \%$ graphitic carbon with a $1.02 \%$ graphitic carbon cutoff (Gignac et 187 al. 2012, Leduc 2013). Liberated graphite flakes occur as oval to sub-rounded particles ranging 188 from 1 to $6 \mathrm{~mm}$ in diameter.

191 Location 
193 village of Montpellier in Ripon Township, within the Composite Arc Belt of the Grenville

194 Province (Fig. 1).

195

196 Field Relationships

197 The geology of the Montpellier graphite showing is summarized in a simplified

198 stratigraphic column in Figure 6. The geology consists of metasedimentary rocks (quartzite, 199 paragneiss, and calc-silicate), metavolcanic rocks (both mafic and felsic), and granitic gneisses 200 and an ortho-amphibolite. These units have experienced polyphase folding (Fig. 7a, b). All units 201 are crosscut by a diabase dyke.

202 The graphite-rich unit contains up to 20 vol.\% graphite and forms lenses of variable sizes

203 at the top of a calc-silicate unit and also within biotite-sillimanite-garnet-rich paragneiss (Fig.

204 6). Disseminated graphite also occurs in the calc-silicate unit (Fig. 7a). The contact between the 205 graphite-bearing paragneiss unit and the overlying impure quartzite unit is irregular (Fig. 7c).

206 The graphite showing is exposed at surface along a vertical cliff about $4 \mathrm{~m}$ high and over 207 a distance of $100 \mathrm{~m}$. This zone is strongly oxidized (Fig. 7b), contains sulfide minerals (mostly 208 pyrrhotite and lesser amounts of pyrite), and it is very friable and weathered along this exposure.

209 Graphite is visible as dark flakes within the competent gneissic unit and when it is weathered,

210 similar to Bissett Creek, graphite flakes are easily picked out of the rock. Graphite flakes are

211 preferentially aligned with the gneissosity. In this particular part of the showing the gneissosity

212 dips shallowly to the west (Taner 1989).

213

214 Petrographic observations 
216 are distinguished: (1) a massive zone with uniformly distributed graphite flakes; and (2) a zone

217 where the graphite flakes are concentrated in nodules. The massive zone occurs in both calc-

218 silicate and paragneiss units whereas the nodular zone is only found in the paragneiss unit.

219 The calc-silicate unit contains 3-5 vol.\% disseminated graphite (Fig. 7a). This unit is

220 composed of variable quantities of recrystallized carbonate (calcite and/or dolomite, about 30-50

221 vol.\%; Fig. 8a), diopside (20-30 vol.\%), plagioclase (20-30 vol.\%) and minor amounts of

222 wollastonite, scapolite, phlogopite, sulfides (pyrrhotite and/or pyrite), and disseminated graphite

223 flakes (3-5 vol.\%). Locally, the amount of disseminated graphite can reach 20 vol.\% (Fig. 8b).

224 Disseminated grains (or blebs) of sphalerite ( $\mathrm{mm}$ to $\mathrm{cm}$ in size) occur within the calc-silicate

225 unit. Graphite mineralization is stratiform at the top of calc-silicate unit.

226 Biotite-sillimanite-garnet-rich paragneiss lies beneath the most graphite-rich horizon

227 (Fig. 6). From the contact with the lower calc-silicate unit, the proportion of graphite flakes

228 progressively increases up section within biotite-rich paragneiss. This unit contains coarse-

229 grained garnet and biotite. Graphite is intergrown with biotite (Fig. 8c, d) and is found along 230 cracks in garnet (Fig. 8c).

232 Economic Geology

233 The graphitic carbon contents of the graphitic units from the main outcrop are

234 summarized in Table 2. Samples were analyzed for graphitic carbon at SGS Laboratories using 235 the CSA05V analytical package. Graphitic carbon contents range from $\sim 1$ to $20 \mathrm{wt} . \%$, with more 236 than half the values above $10 \mathrm{wt. \%}$. Individual graphite grains are millimeters in length (Fig. 8e, 237 f). The average grade of this main outcrop is $13.6 \mathrm{wt} \% \%$ graphitic carbon. Graphite mineralization 
238 continues beneath the impure quartzite unit and within the biotite-sillimanite-garnet-rich

239 paragneiss. Mineralized zones vary in thickness from 0.2 to $4.8 \mathrm{~m}$ and are laterally continuous

240 over $100 \mathrm{~m}$. Graphite-rich zones are composed of friable material that form lenses with graphite

241 flakes of about $1 \mathrm{~mm}$ in size.

243 CARBOn ISOTOPE ANALYSIS OF GRAPHITE

244 Methods

245 Twelve samples were selected for carbon isotope analysis of graphite (eight from Bissett

246 Creek and four from Montpellier). Six samples from Bissett Creek were sampled from drill core, 247 one from a hand sample (BC-0) and one was a graphite concentrate from the mill (BC-M). Four 248 samples were collected from drill core from the Montpellier prospect. With the exception of the 249 mill sample from Bissett Creek, all rocks were crushed by hand and graphite was hand-picked 250 under a binocular microscope. For the mill sample, an aliquot of the graphite product was used.

251 The carbon isotopic compositions of the graphite separates were analyzed at the 252 Laboratory for Stable Isotope Science at the University of Western Ontario. The refractory 253 nature of the graphite presented challenges for some samples and hence a range of analytical 254 approaches were used. First, all samples were analyzed using a Costech 4010 Elemental 255 Analyzer connected in continuous flow mode to a Thermo Scientific Delta ${ }^{\text {PLUS }}$ XL mass 256 spectrometer. About $0.2-0.6 \mathrm{mg}$ of sample was wrapped in tin capsules, prior to combustion at $2571020^{\circ} \mathrm{C}$. These analyses were conducted twice, once without and once with addition of $\sim 1 \mathrm{mg}$ of $258 \mathrm{~V}_{2} \mathrm{O}_{5}$. The latter was added as extra oxidant to facilitate combustion. Samples were calibrated to 259 VPDB using the accepted values for USGS40 and USGS41 (Qi et al. 2003). 
261 (1991). Graphite $(\sim 1.2-1.5 \mathrm{mg})$ was added to a quartz tube, along with $600 \mathrm{mg}$ of $\mathrm{CuO}$ and 500

$262 \mathrm{mg} \mathrm{Cu}$. The evacuated and sealed quartz tubes were then combusted at $900^{\circ} \mathrm{C}$ for two hours and

263 cooled overnight. Because visible graphite still remained in the quartz tubes, they were

264 combusted again for a further 3 hours at $1000^{\circ} \mathrm{C}$, prior to being allowed to cool overnight. The

265 carbon dioxide was then released, cryogenically purified, and then analyzed using a Micromass

266 Optima dual inlet isotope ratio mass spectrometer. Samples were calibrated to VPDB using

267 accepted values for NBS-19 and L-SVEC (Coplen et al. 2006a).

268 All results are reported in the normal delta notation relative to VPDB (Coplen et al., 269 2006b). Comparable results were obtained for all methods. A $\delta^{13} \mathrm{C}$ of $-15.9 \pm 0.2 \%$ (2SD; $\left.n=8\right)$

270 was obtained for USGS24 graphite, as compared to its accepted value $-16.0 \pm 0.1 \%$ (2SD). A

$271 \delta^{13} \mathrm{C}$ of $-25.7 \pm 0.2 \%$ o $(\mathrm{SD} ; \mathrm{n}=5)$ was obtained for the internal laboratory carbon standard, as

272 compared to its accepted value of $-25.7 \pm 0.2 \%$ (SD). Reproducibility (SD) of samples ranged

273 from \pm 0.1 to $\pm 0.7 \%$, and averaged $\pm 0.3 \%$ (Table 3 ).

274

275 Results

276 The $\delta^{13} \mathrm{C}$ of graphite in this study is summarized in Table 3 and in Figure 9. For the

277 Bissett Creek deposit, the carbon isotope compositions have a wide range, varying from -29 to -

$278 \quad 17 \%$ and yield an average value of $-23 \%$. For the Montpellier showing, measured compositions

279 range from -18 to $-14 \%$ with an average of $-16 \%$.

281 DISCUSSION

282 Metamorphic versus hydrothermal graphite 
284 precipitation from carbonic fluids and/or melts (Pasteris 1999, Luque et al. 2014). Syngenetic (or 285 'metamorphic') graphite deposits are generally found in high-grade metamorphic rocks and the 286 graphite is disseminated in flake form (Luque et al. 2014). Individual graphite grains usually 287 contain impurities of metamorphic minerals (Mitchell 1993) and graphite is found within the 288 matrix assemblage and not in pore spaces (Bernard \& Papineau 2014). The carbon content of 289 graphite in these deposits generally ranges from 75 to $97 \%$ and individual crystals are generally 290 millimeters in size (Mitchell 1993).

291 Epigenetic (or 'vein graphite') deposits are also usually found in high-grade metamorphic 292 rocks, but they are spatially associated with fracture or vein sets (e.g. Rumble and Hoering 293 1986b, Kehelpannala \& Francis 2001). Graphite in these deposits is nearly pure with average 294 carbon contents of $\sim 99 \%$ (Mitchell 1993). Graphite occurs as nearly monomineralic veins or 295 nodules that are centimeters to decimeters in size (Barrenechea et al. 2009, Luque et al. 2014). 296 Individual crystals are large and generally centimeters in size (Mitchell 1993).

297 Four specific petrographic and field observations support the metamorphic (syngenetic) 298 model for graphite mineralization at both Bissett Creek and Montpellier. First, graphite is 299 disseminated throughout the graphitic units and is not located along fracture sets or associated 300 with veins. At Montpellier, some graphite occurs in nodules, but graphite represents less than 30 301 vol.\% of the mineral assemblage, which is inconsistent with nearly monomineralic veins that are 302 characteristic of epigenetic graphite deposits. Second, individual graphite flakes from Bissett 303 Creek and Montpellier can contain up 20-30 vol.\% interlayered biotite. Again, this is 304 incompatible with the relatively pure ( $99 \%)$ graphite from epigenetic deposits. Third, individual 305 graphite flake sizes are on the order of millimeters, which is consistent with other syngenetic 
graphite deposits (e.g. Mitchell 1993). Fourth, graphite flakes are intergrown with metamorphic

307 minerals including biotite and garnet (Fig. 4c, 8c), which supports a metamorphic origin for the 308 graphite. Taken together, these different petrological and field observations are most consistent 309 with a metamorphic model of graphite mineralization and are incompatible with the epigenetic 310 model of graphite deposition.

Origin of carbon responsible for graphite mineralization

313 There are three main sources of carbon that form graphite: (1) carbon from organic

314 materials, (2) carbon from the devolatilization of carbonate minerals, and (3) carbon from mantle

315 sources (Luque et al. 2012). Each of these sources has a characteristic range of $\delta^{13} \mathrm{C}$. Most

316 Proterozoic organic matter has $\delta^{13} \mathrm{C}$ that ranges from -40 to $-10 \%$ (Schidlowski 1988, 2001).

317 The $\delta^{13} \mathrm{C}$ of carbon derived from the mantle is approximately $-5 \%$ (e.g., Deines 2002). Marine

318 carbonates generally have compositions around $\sim 0 \%$ (e.g., Keith \& Weber 1964). The

319 compositions of these sources are summarized in Figure 9. The carbon isotope compositions of

320 these sources, however, can only be compared with measured graphite $\delta^{13} \mathrm{C}$ if the latter has not

321 been significantly fractionated during metamorphism.

322 There are two main processes that can modify the carbon isotope composition of graphite

323 from that of its source during metamorphism. Devolitilization of organic material can shift $\delta^{13} \mathrm{C}$

324 by up to 5\% (e.g., Barker \& Friedman 1969, Wada et al. 1994), usually due to the release of

325 isotopically light carbon during the production of methane (e.g., Luque et al. 2012). Most

326 studies, however, document shifts of 1\%o (e.g., Hahn-Weinheimer \& Hirner, 1981). The second

327 process is carbon isotope exchange between graphite and inorganic material (e.g. carbonate

328 minerals). 
330 carbonate minerals and/or carbonic fluid derived from their breakdown) with different carbon

331 isotope compositions leads to isotopic exchange during metamorphism. The amount of isotope

332 fractionation during carbon isotope exchange is mainly a function of temperature (Dunn \&

333 Valley 1992). This process is particularly important at relatively low metamorphic temperatures.

334 For example, the calibration of Dunn \& Valley (1992) for calcite-graphite isotope exchange

335 predicts shifts of $\sim 10 \%$ at $400^{\circ} \mathrm{C}$ and $\sim 6 \%$ at $600^{\circ} \mathrm{C}$. High-temperature metamorphism (e.g.

336 amphibolite and granulite facies) promotes efficient isotope exchange between these minerals

337 and isotope fractionation is expected to be only a few per mil (e.g., Dunn \& Valley 1992). This is

338 supported by graphite in metamorphic rocks that has $\delta^{13} \mathrm{C}$ similar to the primary organic material

339 inferred to be the source of carbon (e.g., Barker \& Friedman 1969, Weis et al. 1981, Crawford \&

340 Valley 1990). Because mineralization at Bissett Creek and Montpellier occurs in amphibolite-to

341 granulite-facies gneisses (see Rivers et al. 2012 and references therein), the carbon isotope

342 compositions of graphite from Bissett Creek and Montpellier are expected to be within a few per

343 mil of that of the source of the carbon.

344 The $\delta^{13} \mathrm{C}$ compositions of graphite from both deposits show a continuum of values from

$345-29$ to $-14 \%$ o that is consistent with carbon derived from organic materials (Schidlowski 1988,

346 2001). Graphite from Montpellier is enriched in ${ }^{13} \mathrm{C}$ relative to graphite from Bissett Creek,

347 which may reflect a more ${ }^{13} \mathrm{C}$-rich source of carbon or isotopic exchange between carbonate

348 minerals and graphite. Although carbonate minerals are not currently present at the Bissett Creek

349 deposit, the diopside-tremolite-biotite assemblage in the calc-silicate unit was likely derived

350 from decarbonation reactions involving the breakdown of calcite and dolomite (e.g., Valley \&

351 Essene 1980). Graphite from a calc-silicate sample (MP-3) has the highest $\delta^{13} \mathrm{C}$ of the Bissett 
352 Creek samples (Table 3) and plots within the range of measured compositions from the

353 Montpellier occurrence (Fig. 9). Therefore, the continuum of graphite $\delta^{13} \mathrm{C}$ compositions may

354 represent a measure of the contribution of isotope exchange between organic carbon and

355 carbonic fluids released during the breakdown of carbonate minerals during prograde

356 metamorphism.

357 An alternative model to explain the continuum of $\delta^{13} \mathrm{C}$ for graphite at Bissett Creek is

358 Rayleigh fractionation of metamorphic fluids derived from an initially homogeneous $\delta^{13} \mathrm{C}$

359 reservoir (e.g. Ray and Ramesh, 2000; Ray, 2009). Figure 10 presents the results of a multi-

360 component Rayleigh fractionation model (Ray, 2009); this model considers graphite that

361 precipitated from a mixed $\mathrm{CO}_{2}-\mathrm{CH}_{4}$ metamorphic fluid at $700^{\circ} \mathrm{C}$ derived from a reservoir with

$362 \delta^{13} \mathrm{C}$ of $-26 \pm 2 \%$. The initial molar ratio of $\mathrm{CH}_{4}$ and $\mathrm{CO}_{2}\left(r_{\mathrm{CH} 4-\mathrm{CO} 2}\right)$ in the source fluid was set at

3630.99 to extend the evolution to a nearly complete exhaustion of the source (e.g. Ray, 2009).

364 Modeled graphite $\delta^{13} \mathrm{C}$ ranges from $-32 \%$ initially up to $-17 \%$ when $1 \%$ of the fluid

365 remains (Fig. 10). Therefore, Rayleigh fractionation of an initially homogenous carbon reservoir

366 can also explain the spread of $\delta^{13} \mathrm{C}$ at Bissett Creek. Considering the paucity of carbonate

367 minerals and the relatively minor amount of calc-silicates at Bissett Creek, the Rayleigh

368 fractionation model is our preferred interpretation for the continuum of $\delta^{13} \mathrm{C}$ of graphite from this

369 locality.

370 The abundance of carbonate units at the Montpellier occurrence may have resulted in

371 higher graphite $\delta^{13} \mathrm{C}$ than graphite from the carbonate-deficient Bissett Creek Deposit. Similar to

372 Bissett Creek, however, the spread in $\delta^{13} \mathrm{C}$ of graphite may also represent Rayleigh fractionation

373 of an initially homogeneous source. In either interpretation, the carbon responsible for graphite

374 mineralization is mostly biotic in origin at both Montpellier and Bissett Creek. 
376 associated with carbonate units (e.g., Mackinnon and LeBaron 1990, 1992). The results of this

377 study suggest that the source of carbon for graphite precipitation is principally biogenic even in

378 the carbonate-rich Montpellier occurrence. Therefore, the contribution of carbon from the

379 decarbonitization of carbonate minerals may be relatively minor. It remains to be tested if this

380 holds true for other carbonate-hosted graphite deposits in the Grenville Province.

382 CONCLUSIONS

383 The Bissett Creek deposit and the Montpellier showing in the southwestern Grenville 384 Province contain disseminated graphite mineralization and graphite morphologies that are 385 consistent with a metamorphic origin. Carbon isotope compositions of graphite from both 386 deposits support a biogenic source for the carbon and the spread in graphite $\delta^{13} \mathrm{C}$ can be 387 generated through a Rayleigh fractionation process. A minor contribution of carbon from the 388 devolatilization of carbonate minerals is also possible at Montpellier. In general, the results of 389 this study suggest that graphite deposits in the southwestern Grenville Province reflect graphite 390 precipitation from metamorphic fluids derived from the breakdown of biogenic material.

\section{ACKNOWLEDGEMENTS}

393 Mr. Greg Bowes, President of the Northern Graphite Corporation, Ottawa, has kindly authorized 394 the authors to use all their available and confidential data. We thank W.M. Schwerdtner for his 395 critical reading of an earlier version of this manuscript and J.S. Ray and an anonymous reviewer 396 for thorough and constructive reviews. We thank Kim Law for assistance with the stable carbon 397 isotope analyses, and acknowledge the Natural Sciences and Engineering Research Council of 
Canada, the Canada Foundation for Innovation, the Ontario Research Fund and the Canada

Research Chairs program for funding. This is Laboratory for Stable Isotope Science Contribution \#353.

401

402

403

404

405

406

407

408

409

410

\section{REFERENCES}

BARKER, F. \& FRIEDMAN, I. (1969) Carbon isotopes in pelites of the Precambrian Uncompahgre Formation, Needle Mountains, Colorado. Geological Society of America Bulletin 80, 1403-1408.

Barrenechea, J. F., Luque, F. J., Millward, D., Ortega, L., Beyssac, O. \& Rodas, M. (2009) Graphite morphologies from the Borrowdale deposit (NW England, UK): Raman and SIMS data. Contributions to Mineralogy and Petrology 158, 37-51.

Bernard, S. \& Papineau, D. (2014) Graphitic carbons and biosignatures. Elements 10, 435-440.

BoutTon, T.W. (1991) Stable carbon isotope ratios of natural materials. 1. Sample preparation and mass spectrometric analysis. In: Carbon Isotope Techniques. D.C. Coleman and B. Fry (eds.), 155-171, Academic Press, New York.Beyssac, O. \& Rumble, D. (2014) Graphitic Carbon: A Ubiquitous, Diverse, and Useful Geomaterial. Elements 10, 415420.

Carr, S. D., EAston, R. M., Jamieson, R. A. \& Culshaw, N. G. (2000) Geologic transect across the Grenville orogen of Ontario and New York. Canadian Journal of Earth Sciences 37, 193-216.

Coplen, T. B., Brand, W. A., Gehre, M., Gröning, M., Meijer, H. A. J., Toman, B. \& Verkouteren, R. M. (2006a) New guidelines for $\delta^{13}$ C measurements. Analytical Chemistry 78, 2439-2441.

Coplen, T. B., Brand, W. A., Gehre, M., Gröning, M., Meijer, H. A. J., Toman, B. \& Verkouteren, R. M. (2006b) After two decades a second anchor for the VPDB $\delta^{13} \mathrm{C}$ scale. Rapid Communications in Mass Spectrometry 20, 3165-3166.

Crawford, W. A. \& VAlley, J. W. (1990) Origin of graphite in the Pickering gneiss and the Franklin marble, Honey Brook Upland, Pennsylvania Piedmont. Geological Society of America Bulletin 102, 807-811.

DEINES, P. (2002) The carbon isotope geochemistry of mantle xenoliths. Earth-Science Reviews 58, 247-278.

Deines, P., Harris, J. W., Robinson, D. N., Gurney, J. J. \& Shee, S. R. (1991) Carbon and oxygen isotope variations in diamond and graphite eclogites from Orapa, Botswana, and the nitrogen content of their diamonds. Geochimica et Cosmochimica Acta 55, 515-524.

Dunn, S. R. \& VAlley, J. W. (1992) Calcite-graphite isotope thermometry: a test for polymetamorphism in marble, Tudor gabbro aureole, Ontario, Canada. Journal of Metamorphic Geology 10, 487-501. 
Galy, V., Beyssac, O., France-Lanord, C. \& Eglington, T. (2008) Recycling of graphite during Himalayan erosion: a geological stabilization of carbon in the crust. Science $\mathbf{3 2 2}$, 943-945.

Garland, M. I. (1987) Graphite in the Central Gneiss Belt of the Grenville Province of Ontario; Ontario Geological Survey, Ministry of the Northern Development and Mines Ontario Open File Report 5649, 275 pp.

Gignac, L., Marchand, R., Menard, R., Phillips, A., Aiken, S. R., Bouajila, A., Menard, N., Houds, D., Thibert, F., Rousseau, G., Champagne, A. (2012) Feasibility study: Bissett Creek Graphite Project, Ontario, Canada. Technical report by G Mining Service Inc. for Northern Graphite Corporation, 299 pp.

HAHN-Weinheimer, P. \& HiRner, A. (1981) Isotopic evidence for the origin of graphite. Geochemical Journal 15, 9-15.

HEwITT, D.F. (1965) Graphite in Ontario. Ontario department of mines, Industrial Mineral Report no 20,66 pp.

HoritA, J. (2001) Carbon isotope exchange in the system $\mathrm{CO}_{2}-\mathrm{CH}_{4}$ at elevated temperatures. Geochimica et Cosmochimica Acta 65, 1907-1919.

Kehelpannala, K. V. W. \& Francis, M. D. P. L. (2001) Vein graphite deposits of the Kegalle District, Sri Lanka: further evidence for post-metamorphic, fluid-deposited graphite. Gondwana Research 4, 655-656.

KeIth, M. L. \& WebeR, J. N. (1964) Carbon and oxygen isotopic composition of selected limestones and fossils. Geochimica et Cosmochimica Acta 28, 1787-1816.

LANDIS, C. A. (1971) Graphitization of dispersed carbonaceous material in metamorphic rocks. Contributions to Mineralogy and Petrology 30, 34-45.

LEDUC, M. (2013). Preliminary Economic Assessment: NI 43-101F1 TECHNICAL REPORT, for the Northern Graphite Corporation, Bissett Creek Project. Prepared by AGP Mining Consultants Inc. 240 pp.

Luque, F. J., Crespo-Feo, E., Barrenechea, J. F. \& Ortega, L. (2012) Carbon isotopes of graphite: Implications on fluid history. Geoscience Frontiers 3, 197-207.

Luque, F. J., Huizenga, J.-M., Crespo-Feo, E., WadA, H., Ortega, L. \& BArRenechea, J. F. (2014) Vein graphite deposits: geological settings, origin, and economic significance. Mineralium Deposita 49, 261-277.

Mackinnon, A. \& LeBAron, P.S. (1990) Major Graphite Occurrences of the Frontenac Axis, Southeastern Ontario. Ontario Geological Survey, Open File Report 5729, 77pp.

MackinNon, A. \& LeBARON, P.S. (1992) Graphite occurrences of the Frontenac axis, Eastern Ontario. Ontario Geological Survey, Mineral Deposit circular 33.

Mitchell, C.J. (1993) Industrial Minerals Laboratory Manual: Flake Graphite. British Geological Survey Technical Report WG/92/30. 31 pages.

Okuyama-Kusunose, Y. \& ITAYA, T. (1987) Metamorphism of carbonaceous material in the Tono contact aureole, Kitakami Mountains, Japan. Journal of Metamorphic Geology 5, 121-139. 
Papineau, D., De Gregorio, B. T., Cody, G. D., Fries, M. D., Mojzsis, S. J., Steele, A., Stroud, R. M. \& Fogel, M. L. (2010a) Ancient graphite in the Eoarchean quartzpyroxene rocks from Akilia in southern West Greenland I: Petrographic and spectroscopic characterization. Geochimica et Cosmochimica Acta 74, 5862-5883.

Papineau, D., De Gregorio, B. T., Stroud, R. M., Steele, A., Pecoits, E., Konhauser, K., WANG, J. \& FogEL, M. L. (2010b) Ancient graphite in the Eoarchean quartz-pyroxene rocks from Akilia in southern West Greenland II: Isotopic and chemical compositions and comparison with Paleoproterozoic banded iron formations. Geochimica et Cosmochimica Acta 74, 5884-5905.

PASTERIS, J. D. (1999) Causes of the uniformly high crystallinity of graphite in large epigenetic deposits. Journal of Metamorphic Geology 17, 779-787.

Pearson, D. G., Boyd, F. R., Haggerty, S. E., Pasteris, J. D., Field, S. W., Nixon, P. H. \& PokHILENKo, N. P. (1994) The characterisation and origin of graphite in cratonic lithospheric mantle: a petrological carbon isotope and Raman spectroscopic study. Contributions to Mineralogy and Petrology 115, 449-466.

Qi, H., Coplen, T. B., Geilmann, H., Brand, W. A. \& Böhlke, J. K. (2003) Two new organic reference materials for $\delta^{13} \mathrm{C}$ and $\delta^{15} \mathrm{~N}$ measurements and a new value for the $\delta^{13} \mathrm{C}$ of NBS 22 oil. Rapid Communications in Mass Spectrometry 17, 2483-2487.

RAY, J. S. \& RAMESH, R. (2000) Rayleigh fractionation of stable isotopes from a multicomponent source. Geochimica et Cosmochimica Acta 64, 299-306.

RAY, J. S. (2009) Carbon isotopic variations in fluid-deposited graphite: evidence for multicomponent Rayleigh isotopic fractionation. International Geology Review 51, 45 57.

Rivers, T., Culshaw, N., Hynes, A., Indares, A., Jamieson, R. \& Martignole, J. (2012) The Grenville Orogen-A post-Lithoprobe perspective In Tectonic styles in Canada: The LiTHOPROBE perspective. (J. A. Percival, F. A. CoOK \& R. M. Clowes, edS). Geological Association of Canada Special Paper, 97-238.

Rivers, T. \& Schwerdtner, W. (2015) Post-peak Evolution of the Muskoka Domain, Western Grenville Province: Ductile Detachment Zone in a Crustal-scale Metamorphic Core Complex. Geoscience Canada 42, 403-436.

Rumble, D. (2014) Hydrothermal Graphitic Carbon. Elements 10, 427-433.

Rumble, D. \& Hoering, T. C. (1986a) Carbon isotope geochemistry of graphite vein deposits from New Hampshire, U.S.A. Geochimica et Cosmochimica Acta 50, 1239-1247.

Rumble, D., Duke, E. F. \& Hoering, T. L. (1986b) Hydrothermal graphite in New Hampshire: Evidence of carbon mobility during regional metamorphism. Geology 14, 452-455.

Sangster, A. L., Gauthier, M. \& Gower, C. F. (1992) Metallogeny of structural zones, Grenville Province, northeastern North America. Precambrian Research 58, 401-426.

SAntosh, M. \& OMORI, S. (2008) $\mathrm{CO}_{2}$ flushing: A plate tectonic perspective. Gondwana Research 13, 86-102. 
Scheele, N. \& Hoefs, J. (1992) Carbon isotope fractionation between calcite, graphite and $\mathrm{CO}_{2}$ : an experimental study. Contributions to Mineralogy and Petrology 112, 35-45.

SchIDlOwsKi, M. (1988) A 3,800-million-year isotopic record of life from carbon in sedimentary rocks. Nature 333, 313-318.

SCHIDLOWSKI, M. (2001) Carbon isotopes as biogeochemical recorders of life over $3.8 \mathrm{Ga}$ of Earth history: evolution of a concept. Precambrian Research 106, 117-134.

Schulze, D. J., Valley, J. W., Viljoen, K. S., Stiefenhofer, J. \& Spicuzza, M. (1997) Carbon isotope composition of graphite in mantle eclogites. The Journal of Geology 105, 379386.

SIMANDL, G.J. (1989) Inventaire de gites de graphite dans la région de Lachute-Hull-MontLaurier. Ministère de l'Énergie et des Ressources naturelles du Québec, MB 89-05, 21 pp.

Soman, K., Lobzova, R. V. \& Sivadas, K. M. (1986) Geology, genetic types, and origin of graphite in South Kerala, India. Economic Geology 81, 997-1002.

SPENCE, H.S. (1920) Graphite. Department of Mines, Canada, Publication no 511, 250 pp.

TANER, M.F. (1989) Évaluation du potentiel en graphite de la propreté Ripon, dans le rang $V$ et des lots 54 et 55 du canton Ripon, Comté de Papineau, Québec. Ministère de l'Énergie et des Ressources naturelles du Québec, rapport GM 58585, 20 pp.

TANer, M.F. (2010) Results of the 2010 Drilling Campaign for the Bissett Creek Graphite Property, Maria Township, Ontario (NTS 31 L/01). Northern Graphite Corporation, 93 pp.

TANER, M.F. (2013) Results of the 2012 Drilling Campaign for the Bissett Creek Graphite Property, Maria Township, Ontario (NTS 31 L/01). Northern Graphite Corporation, 112 pp.

VAlley, J. W. \& EsSEne, E. J. (1980) Calc-silicate reactions in Adirondack marbles: The role of fluids and solid solutions: Summary. Geological Society of America Bulletin 91, 114-117.

ViLjoen, K. S. (1995) Graphite- and diamond-bearing eclogite xenoliths from the Bellsbank kimberlites, Northern Cape, South Africa. Contributions to Mineralogy and Petrology 121, 414-423.

Wada, H., Tomita, T., Matsuura, K., Tuchi, K., Ito, M. \& MorikiYo, T. (1994) Graphitization of carbonaceous matter during metamorphism with references to carbonate and pelitic rocks of contact and regional metamorphisms, Japan. Contributions to Mineralogy and Petrology 118, 217-228.

Weis, P. L., Friedman, I. \& Gleason, J. P. (1981) The origin of epigenetic graphite: evidence from isotopes. Geochimica et Cosmochimica Acta 45, 2325-2332.

Wynne-EdWARds, H.R. (1972). The Grenville Province. In Variations in tectonic styles in Canad (R.A. PRICE \& R.J.W. DouglAS, ED). Geological Association of Canada, $25^{\text {th }}$ anniversary volume, Special Paper 11: 263-334. 


\section{Figure CAPTIONS}

FIG. 1. Simplified map of the Grenville Province with the location of the Bissett Creek graphite deposit and the Montpellier graphite showing (modified from Rivers et al., 2012). ABT: Allochthon Boundary Thrust, CABTZ: Composite Arc Boundary Thrust Zone, CAB: Composite Arc Belt, CGB: Central Gneiss Belt, FAB: Frontenac-Adirondack Belt, PSD: Parry Sound Domain.

FIG. 2. Field relationships of the Bissett Creek deposit. (a) Folded leucosome in the barren (no graphite) gneiss unit. (b) Gossan at the surface of a graphitic gneiss. (c) Pegmatite cutting foliation in the host graphitic gneiss. (d) Sub-vertical lamprophyre dyke cutting foliation in the host graphitic gneiss.

FIG. 3. Gneisses at the Bissett Creek deposit. (a) Biotite-rich quartzofeldspathic gneiss with graphite-rich melanosome. (b) Diopside-tremolite-biotite gneiss with graphite-rich melanosome. (c) Biotite-sillimanite-garnet gneiss with graphite- and biotite-rich melanosome. (d) Barren gneiss with pink leucosome.

FIG. 4. Microstructures of graphitic gneisses from the Bissett Creek deposit. (a) Quartzofeldspathic gneiss with disseminated graphite flakes (plane-polarized light). (b) Coarsegrained graphite in biotite-rich quartzofeldspathic gneiss (plane-polarized light). (c) Intergrown biotite and graphite in the biotite-rich quartzofeldspathic gneiss (plane-polarized light). (d) Disseminated graphite in a diopside-tremolite gneiss in plane polarized light (ppl; top left) and cross-polarized light (xpl; bottom right).

FIG. 5. Graphitic carbon contents of the two dominant graphitic units at the Bissett Creek deposit. Whiskers extend to the lowest and highest datum inside 1.5 times the interquartile range

FIG. 6. A simplified stratigraphic column of the geology of the Montpellier Graphite showing (modified from Taner 1989). 1. Impure quartzite, containing locally biotite-rich paragneiss (1a) and some monzonitic gneiss (1b). 2 Biotite-sillimanite-garnet-rich paragneiss with some graphite-rich zones. 3 Graphite rich zones (10 to $20 \mathrm{wt} \% \%$ graphitic carbon). 4. Calc-silicate unit; (4a) containing 3-5 wt.\% graphitic carbon; (4b) diopside-rich marble; (4c) marble. 5. Biotite-rich paragneiss without graphite flakes. 6 Hornblende and biotite-rich gneiss. 7. Granitic gneiss. 8 . (Ortho-) amphibolite. 9. Late diabase dyke.

FIG. 7. Rock types and field relationships of the Montpellier Graphite showing. (a) An exposure of the main graphite-rich calc-silicate unit (UTM 4902260m E, 5077102m N; NAD83, Zone 17). Graphite is disseminated throughout the outcrop. (b) Recumbently folded calc-silicate unit (c) Irregular contact between the quartzite and paragneiss units.

FIG. 8. Microstructures of graphitic gneisses from the Montpellier graphite showing. (a) Combination of plane-polarized (ppl; top left) and cross-polarized (xpl; bottom right) images showing the association of carbonate minerals with graphite flakes in the calc-silicate unit. (b) Thin section scan showing disseminated graphite flakes in the calc-silicate unit (plane-polarized light). (c) Garnet associated with biotite and graphite in the paragneiss unit (plane-polarized 
601 light). (d) Thin section scan showing coarse-grained graphite flakes intergrown with biotite 602 (plane-polarized light). (e) Coarse-grained graphite in the graphite-rich zone (plane-polarized 603 light). (f) Thin section scan (plane-polarized light) showing oriented graphite flakes in a 604 graphite-rich layer.

605

606 FIG. 9. Summary of $\delta^{13} \mathrm{C}$ of graphite from Bissett Creek and Montpellier along with the variation 607 in $\delta^{13} \mathrm{C}$ of different sources of carbon. The compositions of organic carbon (at $\sim 1 \mathrm{Ga}$ ) and recent 608 marine carbonate are from Schidlowki (2001). The compositions of mantle graphite are compiled 609 from Deines et al. (1991), Pearson et al. (1994), Viljoen (1995) and Schulze (1997). On the box610 and-whisker plots, the whiskers extend to the lowest and highest datum inside 1.5 times the 611 interquartile range and outliers are outside of this range.

612

613 FIG. 10. Results of a multicomponent Rayleigh fractionation model (Ray, 2009) for a starting 614 source composition of $\delta^{13} \mathrm{C}=-26 \pm 2 \%$, a temperature of $700^{\circ} \mathrm{C}$ and $\mathrm{r}_{\mathrm{CH} 4-\mathrm{CO} 2}=0.99$. The 615 graphite-fluid and $\mathrm{CO}_{2}-\mathrm{CH}_{4}$ fractionation factors at this temperature are from Scheele and Hoefs 616 (1992) and Horita (2001). 
617 TABLE 1. Graphitic carbon contents of select samples from Bissett Creek.

618

\begin{tabular}{clc}
\hline Sample ID: & Rock Type & Graphitic C (wt. \%) \\
\hline BC03 & Bt-Rich QF gneiss & 1.29 \\
BC11 & Bt-Rich QF gneiss & 3.63 \\
BC12 & Bt-Rich QF gneiss & 3.15 \\
BC13 & Bt-Rich QF gneiss & 3.16 \\
BC14 & Bt-Rich QF gneiss & 2.92 \\
BC15 & Bt-Rich QF gneiss & 3.88 \\
BC16 & Bt-Rich QF gneiss & 2.76 \\
BC17 & Bt-Rich QF gneiss & 0.86 \\
BC18 & Di-Trem gneiss & 1.05 \\
BC19 & Pegmatite & 1.38 \\
BC20 & Di-Trem gneiss & 2.02 \\
BC21 & Di-Trem gneiss & 1.33 \\
BC22 & Bt-Rich QF gneiss & 1.36 \\
BC23 & Di-Trem gneiss & 1.06 \\
BC24 & Di-Trem gneiss & 1.98 \\
BC25 & Bt-Rich QF gneiss & 2.01 \\
BC26 & Di-Trem gneiss & 0.92 \\
BC27 & Bt-Rich QF gneiss & 2.10 \\
BC28 & Di-Trem gneiss & 2.01 \\
BC29 & Di-Trem gneiss & 3.07 \\
\hline
\end{tabular}

619

620

621

622 
623 TABLE 2. Graphitic carbon content of samples from Montpellier.

624

\begin{tabular}{ll}
\hline Sample & Graphitic C (wt. \%) \\
\hline MPG-01 & 0.82 \\
MPG-02 & 1.94 \\
MPG-03 & 14.4 \\
MPG-04 & 2.69 \\
805 & 9.75 \\
806 & 9.86 \\
807 & 10.66 \\
808 & 14.8 \\
809 & 16.36 \\
810 & 20.42 \\
811 & 19.51 \\
\hline
\end{tabular}

625

626

627

628

TABLE 3. Carbon isotope results for graphite from Bissett Creek and Montpellier.

\begin{tabular}{|c|c|c|}
\hline Sample & Rock Type & $\begin{array}{c}\delta^{13} \mathrm{C} \\
(\%, \mathrm{VPDB})\end{array}$ \\
\hline \multicolumn{3}{|c|}{ Bissett Creek } \\
\hline BC-0 & Bt-Rich QF gneiss & $-24.8 \pm 0.2(\mathrm{n}=8)^{*}$ \\
\hline BC-M & Bulk sample from mill & $-21.2 \pm 0.2(\mathrm{n}=2)$ \\
\hline BC-10 & Bt-Rich QF gneiss & $-29.1 \pm 0.1(\mathrm{n}=3)$ \\
\hline BC-11 & Bt-Rich QF gneiss & $-18.8 \pm 0.7(n=3)$ \\
\hline $\mathrm{BC}-12$ & Bt-Rich QF gneiss & $-26.7(\mathrm{n}=1)$ \\
\hline BC-13B & Bt-Rich QF gneiss & $-17.4 \pm 0.2(\mathrm{n}=3)$ \\
\hline BC-14 & Bt-Rich QF gneiss & $-22.5 \pm 0.6(\mathrm{n}=4)$ \\
\hline BC-15 & Bt-Rich QF gneiss & $-20.2(\mathrm{n}=1)$ \\
\hline \multicolumn{3}{|c|}{ Montpellier } \\
\hline MP-2 & Paragneiss & $-14.3 \pm 0.5(n=4)$ \\
\hline MP-3 & Calc-silicate gneiss & $-13.6(n=1)$ \\
\hline MP-4 & Paragneiss & $-16.9 \pm 0.2(\mathrm{n}=5)$ \\
\hline MP-5 & Paragneiss & $-17.7 \pm 0.2(\mathrm{n}=5)$ \\
\hline
\end{tabular}




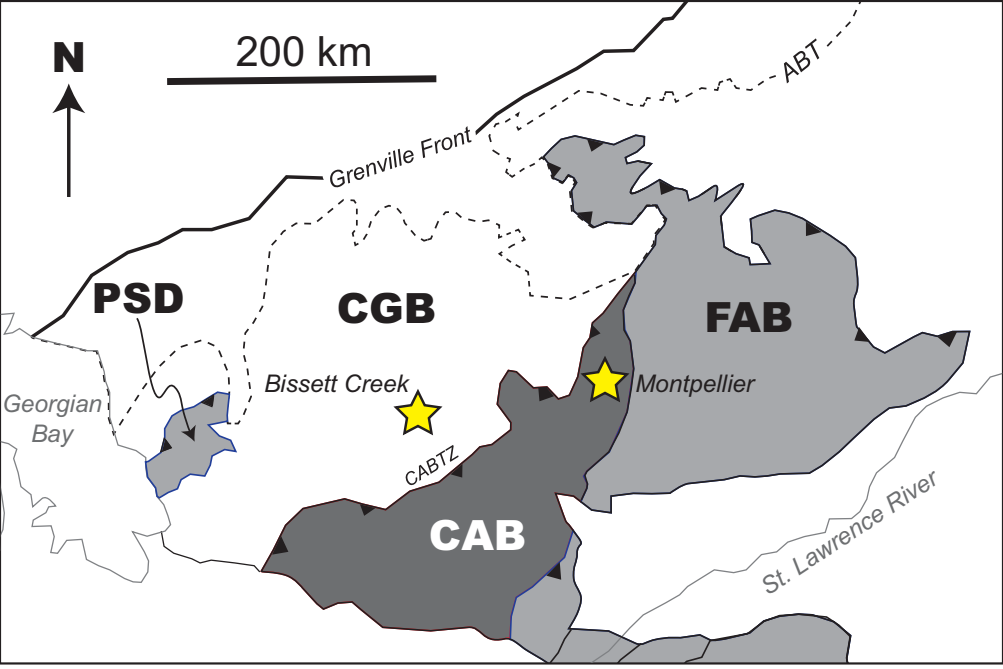

\section{Figure 1}





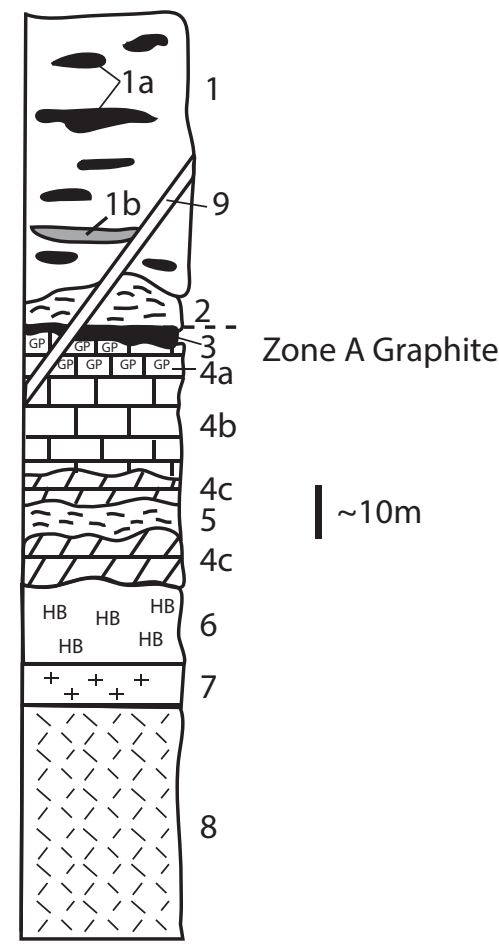

Figure 6 

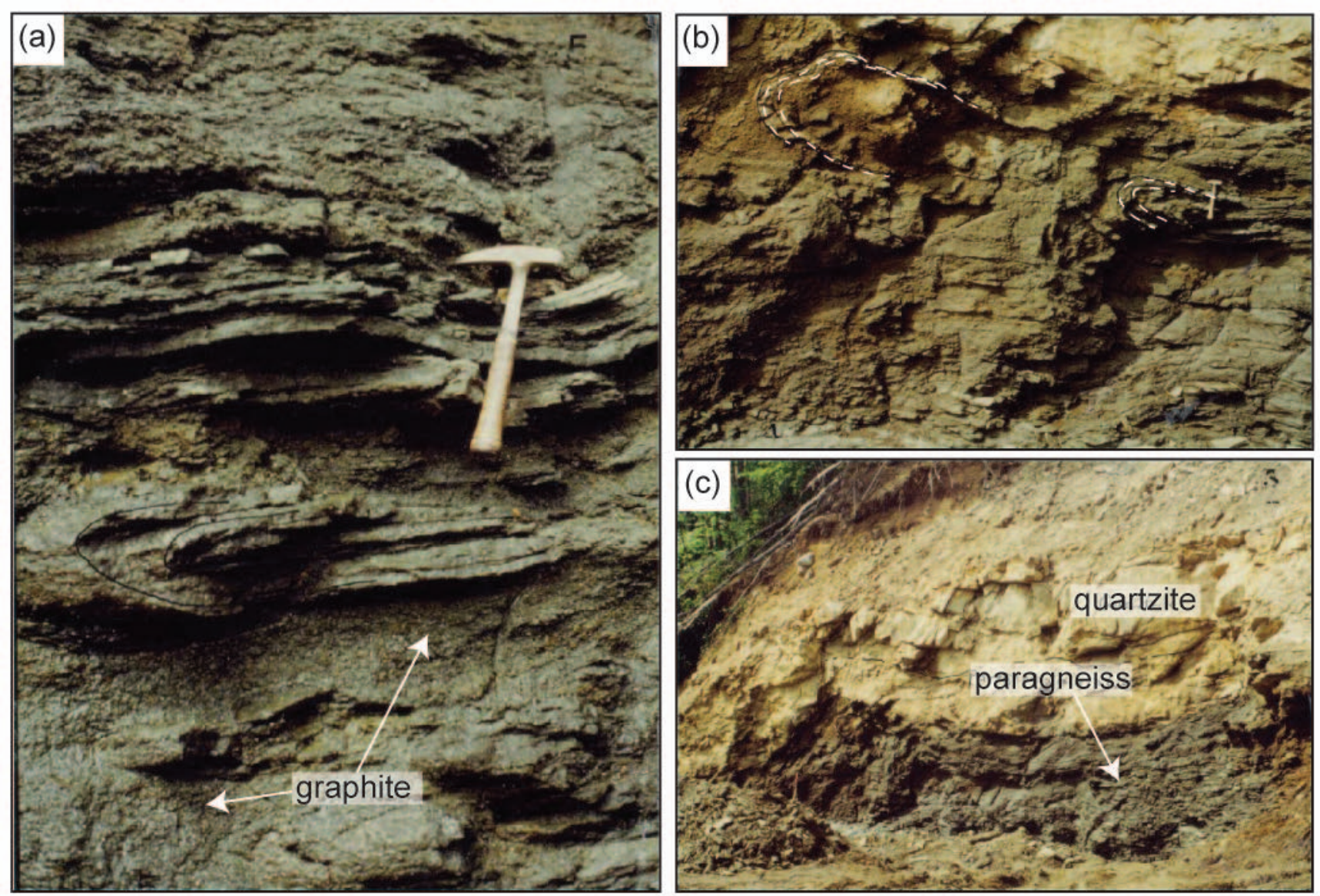

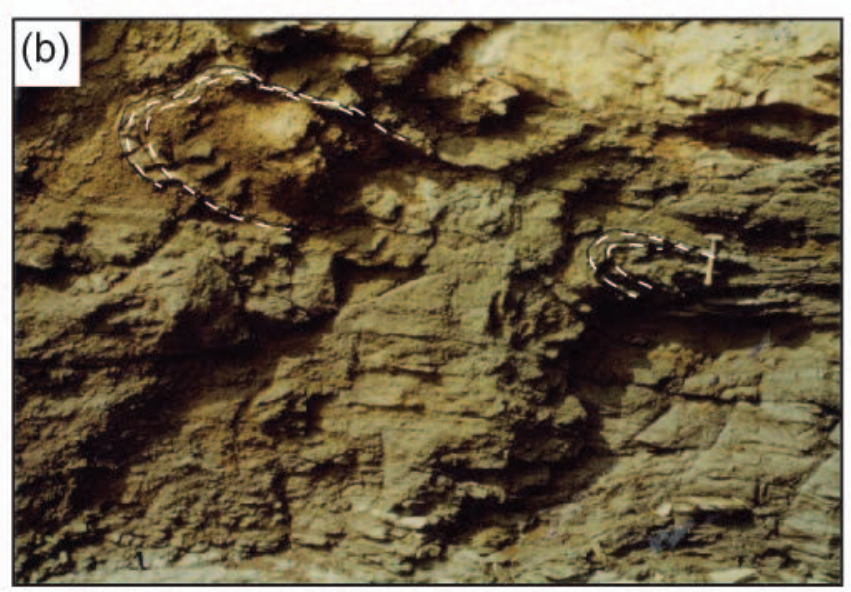

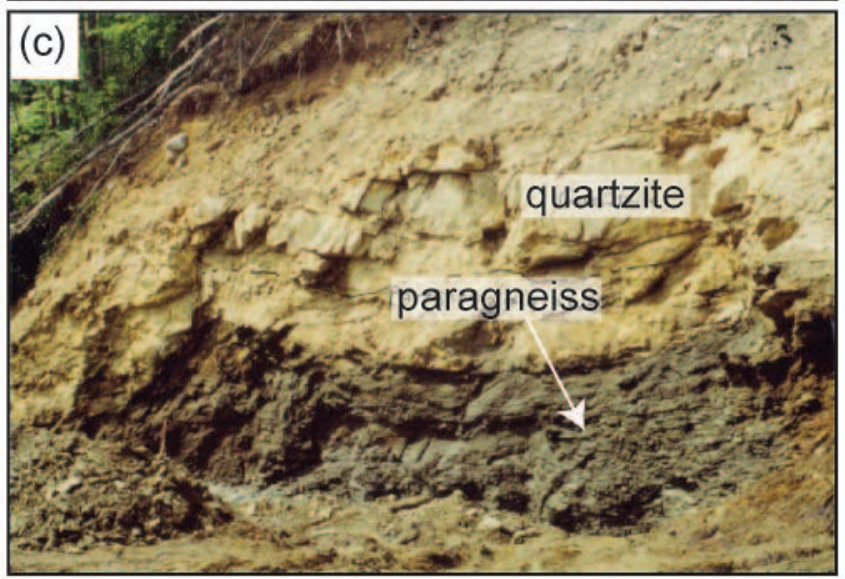

Figure 7 


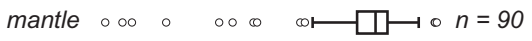

organic carbon

Measured graphite values

Montpellier

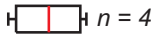

Bissett Creek

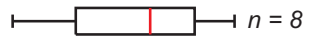

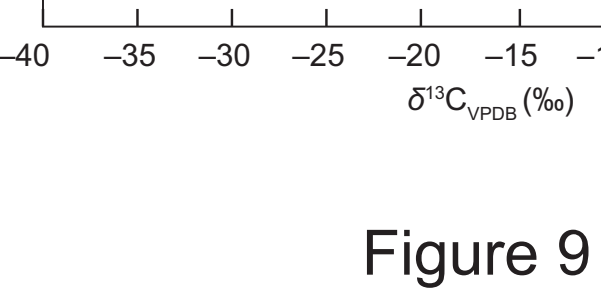




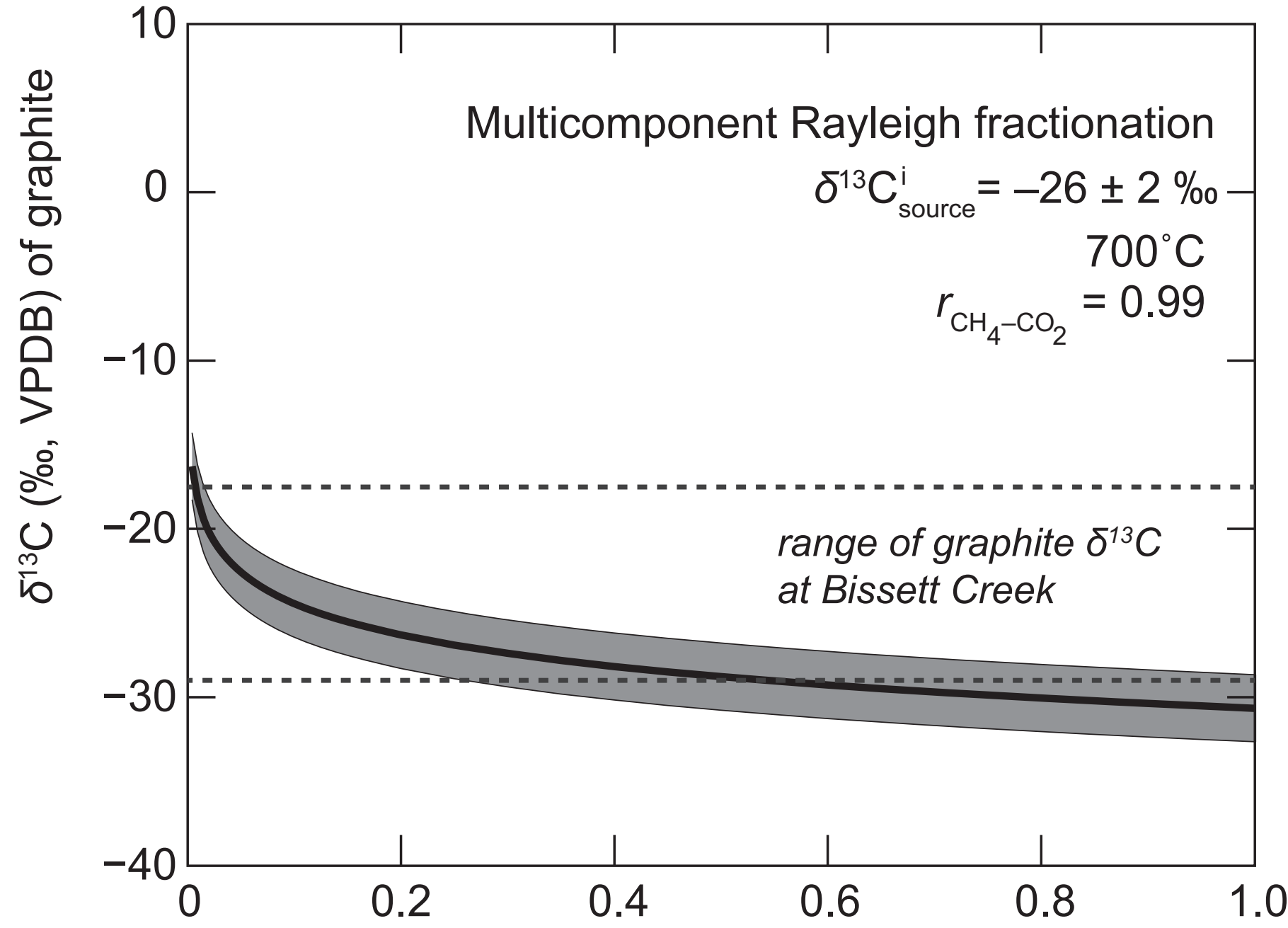

fraction of remaining source

\section{Figure 10}

